\title{
Psychosocial Development of Patients with Disorder of Sexual Development vis-à-vis Hypospadias
}

\author{
Dr. Ratika Samtani ${ }^{1}$
}

\begin{abstract}
:
This article refers to the psychological consequences of hypospadias, a male congenital abnormality of the urethra. Hypospadias is defined as an abnormal opening of the urethra on the underside of the penis and is a frequently found malformation with an incidence of 1 per 300 males. The article reviews the research relating to the psychosocial aspects of Hypospadias and the outcome of surgery on psychosocial development of the affected. Due to the fact that hypospadias is a psychological condition as well as a physical one, this paper discusses the influence of the condition on the patient's psychosocial and psychosexual development. The review highlights that severity of hypospadias influences a more negative genital appraisal and increased behavioral problems. It can be suggested that early identification of Hypospadias and surgery at birth may generate a better surgical outcome and sound psychosocial and psychosexual development
\end{abstract}

Keywords: Hypospadias, Psychological consequences, severe forms, sexuality, behavior problems

Hypospadias is defined as an abnormal opening of the urethra on the underside of the penis and is a frequently found malformation with an incidence of 1 per 300 males. This malformation affects the genital development and it may pose certain psychological repercussions. The birth of an intersex child or a child born with any disorder of sexual development is traumatizing for the family and prompts a long term management strategy. Psychosocial aspects of the treatment of disorders of sex development (DSDs) concerns gender assignment, information management and communication, timing of medical interventions, consequences of surgery and sexuality (Kettinis et al, 2010). Disorders such as severe hypospadias presenting as ambiguous genitalia have serious and potentially life-long consequences for affected individuals. Genetic males with severe hypospadias are wrongly brought up as females. At puberty, they are reassigned as males after undergoing surgery for correction of hypospadias which can be a traumatizing experience for the patients. Surgical reconstruction of the urethra and straightening of the penis is necessary to ensure urinating in the standing position and full adult sexual functioning.

${ }^{1}$ Assistant Professor, Amity Institute of Anthropology, Amity University, Sector-125, Noida distribution, and reproduction in any Medium, provided the original work is properly cited. 
Another important goal of hypospadias surgery is the achievement of a cosmetic appearance of the penis that is as "normal" as possible. Although more than 150 surgical techniques to correct hypospadias have been described (Levitt \& Reda, 1988), studies on psychosocial functioning of hypospadias patients are scarce. Adolescents and young adults who have undergone several repair surgeries for most severe hypospadias, despite a good overall psychosocial and psychosexual adjustment, do report more dissatisfaction adjustment with their penis appearance than peers from general population (Vandendriessche et al., 2010, Mieusset Soulié, 2005).

Studies indicate that adolescents having undergone Hypospadias repair surgery in childhood do not show any significant differences with peers as to gender behavior, age at first sexual intercourse behavior, and attitude towards sexuality (Schönbucher et al., 2008; Mureau et al., 1995; Sandberg et al., 1995)

There are very few studies dealing with the proper management of such disorders so as to prevent the agony of parents resulting from ignorance and social stigma. This article reviews the research relating to the psychosocial aspects of Hypospadias and the outcome of surgery on psychosocial development. Due to the fact that hypospadias is a psychological condition as well as a physical one (Matuszkiewicz et al, 2012), this paper discusses the influence of the condition on the patient's psychosocial and psychosexual development.

\section{METHODS:}

A literature search was conducted for papers that focused on psychosocial adjustment, and the psychosexual development of children, and adolescents with hypospadias in the last 20 years. The following electronic bibliographic databases were searched: Embase, PubMed, and Medline. The searches were carried out using the keywords hypospadias, psychosocial adjustment, social, psychological, sexual behavior, and sexual dysfunction dealing only with the psychological consequences of hypospadias. Eligible publications were limited to psychosocial/sexual adjustment of hypospadias patients in childhood, adolescence and/or adulthood. Papers were included if the study sample comprised individuals with isolated hypospadias cases only.

The papers dealing with the psychological consequences of other urological anomalies were ruled out from the study.

\section{RESULTS:}

The main characteristics of the included studies are summarized in Table I. Six studies were included that had associated comparison data with them. Main weaknesses of the studies included small sample sizes, missing information about medical characteristics and the use of no validated measures. Meta-analysis could not be carried out for the present review as most of the studies comprised of small sample size, with variable experimental designs and missing information. 
TABLE 1: Summary of studies included in the Review

\begin{tabular}{|c|c|c|c|c|c|c|}
\hline $\begin{array}{l}\text { S. } \\
\text { No. }\end{array}$ & Study Reference & $\begin{array}{l}\text { Study } \\
\text { Design }\end{array}$ & \begin{tabular}{|l|} 
Age of \\
Patients
\end{tabular} & $\begin{array}{l}\text { Comparison } \\
\text { Data }\end{array}$ & Severity & Outcomes \\
\hline 1 & $\begin{array}{l}\text { Vandendriesche } \\
\text { et al, } 2010\end{array}$ & $\begin{array}{l}\text { Cross- } \\
\text { Sectional / } 10 \\
\text { boys }\end{array}$ & $\begin{array}{l}11-18 \\
\text { years }\end{array}$ & 10 boys & Mild to severe & $\begin{array}{l}\text { Boys operated on for } \\
\text { Hypospadias appear to } \\
\text { experience normal social, } \\
\text { psychosocial and sexual } \\
\text { development }\end{array}$ \\
\hline 2 & $\begin{array}{l}\text { Mondiani et al, } \\
2002\end{array}$ & $\begin{array}{l}\text { Cross- } \\
\text { Sectional/42 } \\
\text { boys }\end{array}$ & $\begin{array}{l}>90 \% \\
18 \text { years } \\
\text { of age }\end{array}$ & 500 & Mild to severe & $\begin{array}{l}\text { Severity of disease } \\
\text { influences a more negative } \\
\text { genital appraisal and the } \\
\text { number of operations is } \\
\text { correlated only with more } \\
\text { difficulty in initiating contact } \\
\text { with the opposite sex. }\end{array}$ \\
\hline 3 & $\begin{array}{l}\text { Sandberg et al, } \\
2001\end{array}$ & $\begin{array}{l}\text { Case- } \\
\text { Control/175 } \\
\text { Boys }\end{array}$ & $6-10 \mathrm{yrs}$ & $\begin{array}{l}333 \text { age } \\
\text { matched }\end{array}$ & $\begin{array}{l}\text { Glanular (mild) } \\
\text { to perineal } \\
\text { (severe) }\end{array}$ & $\begin{array}{l}\text { More severe anomalies were } \\
\text { associated with increased } \\
\text { behavior problems. }\end{array}$ \\
\hline 4 & $\begin{array}{l}\text { Purschke and } \\
\text { Standke, 1993, }\end{array}$ & $\begin{array}{l}\text { Cross- } \\
\text { sectional/47 }\end{array}$ & $5-13$ yrs & $\begin{array}{l}23 \text { boys after } \\
\text { various } \\
\text { operations } \\
\text { norms }\end{array}$ & $\begin{array}{l}\text { Glanular (mild) } \\
\text { to } \\
\text { Penoscrotal } \\
\text { (severe) }\end{array}$ & $\begin{array}{l}\text { Hypospadiac children } \\
\text { showed strong feelings of } \\
\text { inferiority and an increased } \\
\text { sensibility, proved to be } \\
\text { socially less adapted and } \\
\text { more difficult to train. } \\
\text { Children with mild forms of } \\
\text { hypospadias had a less } \\
\text { striking. effect. More } \\
\text { aggravating mental problems } \\
\text { were noted with increasingly } \\
\text { frequent repetition of } \\
\text { operations. }\end{array}$ \\
\hline 5 & $\begin{array}{l}\text { Mureau et al, } \\
1997\end{array}$ & $\begin{array}{l}\text { Case-Control } \\
116 \\
\text { Hypospadiacs }\end{array}$ & $9-18$ & $\begin{array}{l}88 \text { boys after } \\
\text { hernia } \\
\text { repair }\end{array}$ & $\begin{array}{l}\text { Distal (mild) to } \\
\text { Proximal } \\
\text { (medium) }\end{array}$ & $\begin{array}{l}\text { No significant relationships } \\
\text { of severity of hypospadias } \\
\text { with psychosocial } \\
\text { functioning could be found } \\
\text { Adolescent Hypospadias } \\
\text { patients who were } \\
\text { dissatisfied with their penile } \\
\text { appearance are more at risk } \\
\text { for psycho-social problems. }\end{array}$ \\
\hline
\end{tabular}

\section{DISCUSSION}

Publications on the psychological, social, and sexual development of patients operated on for hypospadias are still rare and deserve attention.

Studies depict contradictory outcomes with respect to social, psychological and sexual development of patients operated on for hypospadias. Boys in the age group 11-18 years after 
surgery appeared to experience normal social, psychosocial and sexual development. On the other hand, children in the age group 5-13 yrs showed strong feelings of inferiority and were observed to socially less adapt.

However, in most of the studies, it was observed that severity of the disease influenced a more negative genital appraisal associated with increased behavioral problems. Sandberg et al, 2001also suggested that more severe anomalies were associated with increased behavior problems and poorer school performance. Purschke and Standke'1993 further emphasized that milder the hypospadias, the effect is less striking as compared to severe cases. According to Mureau et al, 1997 adolescent Hypospadias patients who were dissatisfied with their penile appearance were found to be more at risk for psycho-social problems.

The present review highlights that the increased severity of the hypospadias would result in a more negative genital appraisal and increased behavioral problems. Thought there are contradictions with respect to the age of operation of the patient and its psychological outcome, it can be suggested that early identification of Hypospadias and surgery at infancy may generate a better surgical outcome and sound psychosocial and psychosexual development.

Ambiguity of the genitalia in the newborns still remains a poorly understood subject. There are very few studies dealing with the proper management of such disorders so as to prevent the agony of parents resulting from ignorance and social stigma. In conservative settings, since ambiguity of the genitalia is a sensitive topic of discussion, its information is often kept a secret within families. The true paternity of a boy with hypospadias may also be surreptitious. Emphasis on the importance of counseling the families of Hypospadias patients implies discussing how to deal with the social environment. Appropriate tools must be formulated to identify at risk families and training programmes for at risk families need to be developed and made easily available especially in rural areas. For instance, in Asian Indian context where birth of an intersex child is a social stigma, clinicians should pay extra care and give attention to timely prepare the parents of the consequences of the disorders of sexual development in their child's sexual life. However, more studies are needed to investigate the effects and consequences of Hypospadias on people's life. Efforts should be made for a screening program for hypospadias among newborns, especially among rural areas to prepare families for genital surgery and psychological treatment techniques addressing the aspect of Hypospadias.

\section{REFERENCES}

Berg, R., Svensson, J., Astro“m, G. (1981). Social and sexual adjustment of men operated for hypospadias during childhood: a controlled study. Journal of Urology,125:313-317

Kettenis, P T C. (2010). Psychosocial and psychosexual aspects of disorders of sex development. Best Practice \& Research Clinical Endocrinology \& Metabolism, 24, 325-334

Levitt, SB., \& Reda, E F. (1988). Hypospadias. Pediatric Annals, 17, 48-57. 
Matuszkiewicz, E1., Bargiel-Matusiewicz, K. (2012). Hypospadias--a psychological view. Psychosocial and psychosexual implications. Wiad Lek.;65(1),48-54

Mondaini, N., Ponchietti, R., Bonafe', M., Biscioni, S., Di Loro, F., Agostini, P., Salvestrini, F., Rizzo, M. (2002). Hypospadias: incidence and effects on psychosexual development as evaluated with the Minnesota Multiphasic Personality Inventory Test in a sample of 11,649 young Italian men. Urol Int, 68, 81-85.

Mureau, M. A., Slijper, F. M., Slob, A. K., Verhulst, F .C.(1997). Psychosocial functioning of children, adolescents, and adults following hypospadias surgery: a comparative study. $J$ Pediatr Psychol, 22, 371-387.

Mureau, M.A.M., Slijper F.M.E., Slob, A.K., \& Verhulst F.C. Genital perception of children, adolescents, and adults operated on for hypospadias: A comparative study. Journal of Sex Research, 32,289-298

Purschke, C \& Standke, M. (1993). Psychische Besonderheiten bei Knaben mit Hypospadien [Psychological characteristics of boys with hypospadias]. Pa"diatrisches Grenzgebiet, 31 , 175-185.

Scho“nbucher, V., Schweize, K., Rustige, L., Schu“ tzmann, K., Brunner, F., Richter-Appelt, H. (In press). Sexual Quality of life of individuals with 46,XY disorders of sex development. The Journal of Sexual Medicine.

Sandberg, D.E., Meyer-Bahlburg, H.F.L., Hensle, T.W., Levitt, S.B., Kogan, S.J., Reda, E.F.(2001). Psychosocial adaptation of middle childhood boys with hypospadias after genital surgery. J Pediatr Psychol , 26, 465-475

Sandberg, D. E., Meyer-Bahlburg, H.F. L., Yager, T.J., Hensle, T.W., Levitt, S.B., Kogan, S.J \& Reda, E. F. (1995). Gender development in boys born with hypospadias. Psychoneuroendocrinology, 20,693-709

Vandendriessche, S., Baeyens, D., Van Hoecke, E., Indekeu, A., Hoebeke, P.(2010) Body image and sexuality in adolescents after hypospadias surgery. J Pediatr Urol 6(1), 54-9. doi: 10.1016/j.jpurol.2009.04.009. 